\title{
THE SELECTION OF A SUITABLE MAINTENANCE STRATEGY FOR WIND TURBINES
}

\author{
Jesse A. Andrawus ${ }^{1 *}$, John Watson ${ }^{1}$, Mohammed Kishk ${ }^{2}$ and Allan Adam ${ }^{1}$ \\ ${ }^{1}$ School of Engineering, the Robert Gordon University, Schoolhill Aberdeen, AB10 1FR, UK. \\ 2 The Scott Sutherland School, the Robert Gordon University, Garthdee Road, Aberdeen, \\ AB10 7QB, UK. \\ Email < prs.andrawus@rgu.ac.uk> <j.f.watson@rgu.ac.uk > <m.kishk@rgu.ac.uk> \\ $<$ a.adam@rgu.ac.uk>
}

\begin{abstract}
Common maintenance strategies applied to wind turbines include 'Time-Based' which involves carrying out maintenance tasks at predetermined regular-intervals and 'FailureBased' which entails using a wind turbine until it fails. However, the consequence of failure of critical components limits the adequacy of these strategies to support the current commercial drivers of the wind industry. Reliability-Centred Maintenance (RCM) is a technique used mostly to select appropriate maintenance strategies for physical assets. In this paper, a hybrid of an RCM approach and Asset Life-Cycle Analysis technique is applied to Horizontal-Axis Wind Turbines to identify possible failure modes, causes and the resultant effects on system operation. The failure consequences of critical components are evaluated and expressed in financial terms. Suitable Condition-Based Maintenance activities are identified and assessed over the life-cycle of wind turbines to maximise the return on investment in wind farms.
\end{abstract}

Key words: Wind turbines, Reliability-Centred Maintenance, Failure Mode and Effect Analysis, Asset Life-cycle Analysis, Condition-Based Maintenance. 
NOMENCLATURE

$\alpha=$ Failure rate

$A^{*}=$ Best alternatives

$A_{C R}=$ Annual cost reservation

$A C_{C B M}=$ Annual condition based servicing of drive train

$A M_{c m}=$ Annual maintenance cost of condition monitoring

$B T C=$ Benefit- to-cost ratio

$C_{M T}=$ Cost of material

$C_{L d}=$ Cost of loading

$C_{\text {Old }}=$ Cost of offloading

$C_{T P}=$ Cost of transportation

$C_{C R}=$ Cost of crane hire per day (including driver, mobilisation and demobilisation fee)

$C_{E H}=$ Cost of energy per $\mathrm{kWh}$

$C_{f}=$ Capacity factor

$C_{c m}=$ Capital cost of condition monitoring system

$d=$ Discount rate $(\% / 100)$

$F_{c}=$ Failure consequences

$i=$ Alternative

$L_{R T}=$ Labour rate per hour

$L_{h c}=$ Lead time to hire a crane

$m=$ Decision criteria

$n=$ Number of competing alternatives

$N_{P_{n}}=$ Number of person

$N_{d y}=$ Number of working days

$N_{T}=$ Number of turbines in a wind farm

$N P V_{C B M}=$ Net present Value of Condition Based Maintenance

$N P V_{T B M}=$ Net present Value of Time Based Maintenance

$P W=$ Present worth

$P W A=$ Present worth per annum

$R_{d y}=$ Replacement days including travel time

$S_{i}=$ Total score of alternative

$S_{i j}=$ Alternative ratings

$T A_{C I}=$ Total annual cost of inspection

$T_{P L}=$ Total Production loss

$T C_{L B}=$ Total cost of labour

$T C_{A S}=$ Total cost of access

$T C_{M T}=$ Total cost of material

$T=$ Analysis period

$V_{A T}=$ Value added tax 
$W_{j}=$ Criterion weight

$W_{h r}=$ Work hours per day

$W T_{P R}=$ Wind turbine power rating in kilowatt $(\mathrm{kW})$

\section{INTRODUCTION}

Wind is becoming one of the fastest growing energy sources in many countries seeking to mitigate the effects of global warming and reduce dependency on imported fuels. Very significant financial investments have been made in developing wind farms and the associated grid connection facilities all over the world. Indeed, the wind industry in 2005 spent more than US\$14 billion on installing new generating equipment [1]. Progressively, world generated wind energy has now increased to about 59,322 MW [1] from 2,000 MW in 1990 [2] with an annual average growth rate of 26 percent [3]. With this growth has come the need to improve the productivity of wind turbines and to maximise the return on investment in wind farms. Successful future development will require maintenance strategies that are appropriate (technically feasible and economically viable over the lifecycle of wind turbines), given that, "the net revenue from a wind farm is the revenue generated from sale of electricity less operation and maintenance (O\&M) expenditure" [4]

This paper discusses the current maintenance strategies for wind turbines and identifies the associated problems. The concept and relevance of Reliability Centred Maintenance (RCM) and Asset Life-Cycle Analysis (ALCA) techniques to the wind energy industry are discussed and a Failure Modes and Effects Analysis of a generic horizontal axis wind turbine are presented. A case study is presented to demonstrate the practical application of the hybrid RCM and ALCA to determine suitable Condition Based Maintenance (CBM) activities for a $26 \times 600 \mathrm{~kW}$ wind farm. The commercial viability of the CBM activities is assessed using the ALCA technique taking into account geographical location, intermittent operation and value of generation. Non-financial factors are identified and assessed using a Weighted Evaluation (WE) technique. Uncertainties in the financial calculations are risk assessed using a probabilistic technique of the Crystal Ball Monte Carlo simulation.

\section{RATIONALE AND OBJECTIVE}

Wind turbines are often purchased with a 2-5 years all-in-service contract, which includes warranties, and corrective (failure-based) and preventive (time-based) maintenance strategies [5]. These strategies are usually adopted at the expiration of the contract period to continue the maintenance of wind turbines [6-7].

Failure Based Maintenance (FBM) involves using a wind turbine or any of its components until it fails. This strategy is usually implemented where failure consequences will not result in revenue losses, customers' dissatisfaction or health and safety impact. However, critical component failures within a wind turbine can be catastrophic with severe operational and Health, Safety and Environmental (HSE) consequences.

Time Based Maintenance (TBM) involves carrying out maintenance tasks at predetermined regular-intervals. This strategy is often implemented to avoid invalidating the Original Equipment Manufacturers' (OEM) warranty and to maintain sub-critical machines where the pattern of failure is well known. However, the choice of the correct interval poses a problem as too frequent an interval increases operational costs, wastes production time and unnecessary replacements of components in good condition, whereas, unexpected failures frequently occur between TBM intervals which are too long [8]. Thus, time and resources are usually wasted on maintenance with little knowledge of the current condition of the equipment. 
Condition-Based Maintenance (CBM) is defined as the most cost-effective means of maintaining critical equipment [9-10]. A CBM strategy constitutes maintenance tasks being carried out in response to the deterioration in the condition or performance of an asset or component as indicated by a condition monitoring process [11]. The broad research area of CBM applied to wind turbines and the associated grid connection facilities has largely been ignored, although limited work has been undertaken in monitoring the structural integrity of turbine blades using thermal imaging and acoustic emission [1213]; the use of performance monitoring [4] and temperature monitoring and on-line analysis systems [14-15]. Generally, as reported, this work is considered in isolation, and is not considered within the wider context of a maintenance, integrity and asset management strategy. It is this integration of techniques which form the basis of the research work reported in this paper.

\section{APPROACH AND METHODOLOGY}

A number of approaches exist in asset management to determine the appropriate maintenance strategies for physical assets:

\subsection{Total Productive Maintenance}

This approach evaluates potential causes of asset failure by focusing on the machine, methods of operation, measurement styles, manpower error and materials. It assesses a failure mode by asking 'Why' up to five times, in a bid to trace the problem to its root cause. The approach is used often in the manufacturing sector to treat, tolerate, transfer or terminate a problem [16]. However, Total Productive Maintenance (TPM) is constrained on the specific tools needed to determine which tasks are worth doing in terms of risk consideration and equipment life expectancy [17].

\subsection{Risk Based Inspection}

Risk Based Inspection (RBI) systematically assesses static-equipment to determine appropriate condition monitoring methods for equipment with high likelihood and consequence of failure. It uses risk as a basis for prioritising and managing inspection programs of static-equipment. The approach allows development of equipment-specific inspection plans as well as optimising inspection methods and intervals [18-19]. However, RBI is notably weak in determining how much to spend on inspections and condition monitoring systems and also in pointing to alternative risk-treatment options [17].

\subsection{Reliability-Centred Maintenance}

Reliability-Centred Maintenance (RCM) identifies ways in which components or systems at the design stage or already in operation can fail to perform their intended design functions. The approach focuses on the functions of equipment in order to predict failure modes and the resultant consequences so that suitable maintenance actions can be determined [11, 20]. This makes RCM unique from the other approaches. Moubray [21] explains that no comparable technique exists for identifying the true, safe minimum of what must be done to preserve the functions of physical assets in the way that RCM does. RCM originated in the aircraft industry and has been applied with considerable success in several industrial sectors, for example, Railways [22]; Offshore Oil \& Gas [9]; Manufacturing sector [23] etc.

The entire purpose of maintenance is to ensure that machines continue to do what their users want of them. Therefore the first step in a CBM strategy is to understand what is required of an asset, how this can be affected and the consequences. RCM which is defined as "....a systematic consideration of system functions, the way functions can fail, and a priority-based consideration of safety and economics that identifies applicable and effective preventive maintenance tasks" [24], provides the necessary underlying concepts 
to do this by asking and building upon seven basic questions [11] in the sequence shown below:

- What are the functions and associated desired standards of performance of the asset in its present operating context (functions)?

- In what ways can it fail to fulfil its functions (functional failures)?

- What causes each functional failure (failure modes)?

- What happens when each failure occurs (failure effects)?

- In what way does each failure matter (failure consequences)?

- What should be done to predict or prevent each failure (proactive tasks and task intervals)?

- What should be done if a suitable proactive task cannot be found (default actions)?

RCM alone is limited in determining which maintenance strategies are the most cost effective options available [17]. Therefore, an ALCA technique which is defined as "...the combined evaluation of capital costs with future performance, operating and maintenance implications, life expectancies and eventual disposal or replacement of an asset" [17] is, in this work, incorporated into RCM to assess the commercial viability of CBM activities in comparison to other maintenance options over the life cycle of wind turbines.

\section{APPLICATION OF RCM TO A GENERIC HORIZONTAL AXIS WIND TURBINE}

The first four RCM questions, listed in the previous section, identify ways in which a wind turbine already in operation can fail to perform its design intentions and the resultant effects on the components and systems of the turbine. This is usually referred to as a Failure Mode and Effect Analysis (FMEA).

\subsection{Functions and performance standards of a wind turbine}

The primary function of a wind turbine is to convert wind kinetic energy into electrical energy within a defined speed limit (cut-in and cut-out wind speed). This function is solely considered to minimise complexity in the analysis. The reader is referred to Wind Turbine Standards IEC 61400-22 [25] for other functions and standards of performance.

\subsection{Functional failures}

Three functional failures are defined in view of the primary function stated in section 4.1; these include (i) Complete loss of energy conversion capability (ii) Partial loss of energy conversion capability and (iii) Over speeding. This broad classification permits the analysis of critical components and subsystems that are indispensable to the normal operation of a wind turbine.

\subsection{Failure Mode and Effect Analysis (FMEA)}

Failure modes for the defined functional failures are presented logically in Table 1 . These were further scrutinised sequentially to identify possible causes up to a third level as shown in an extract copy presented in Table 2 . The result of this analysis can be applied to a generic horizontal axis wind turbine.

\section{A CASE STUDY}

In this section, a case study is presented to demonstrate the practical applicability of the approach. The last three RCM questions determine failure consequences and suitable maintenance tasks to mitigate the penalties. Data from a $26 \times 600 \mathrm{~kW}$ onshore wind farm (total capacity of $15.6 \mathrm{MW}$ ) operating at an average capacity factor of $33 \%$ is used to answer the last three questions. The selection of this category of wind farm and turbine is deliberate for a number of reasons; first, onshore wind farms have ease of access for 
maintenance activities; secondly, it has been suggested in [7] that the failure of a lowrated-power wind turbine such as $600 \mathrm{~kW}$ does not greatly affect the revenue generation of a wind farm because wind turbines operate stand-alone and the financial margins in the wind industry is relatively small.

\subsection{Data collation}

Current market prices of major components of a $600 \mathrm{~kW}$ wind turbine, including transportation cost to site, were obtained from manufacturers. Labour requirements for replacements of these components as well as the access costs were obtained from the collaborating wind farm operator (see table 3 ).

Historical failure data pertinent to failure modes of the $600 \mathrm{~kW}$ turbine were labelled as $W T-1-1, W T-1-2, W T-1-3, W T-1-4, W T-1-6$ and $W T-1-8$ (where $W T$ represent "wind turbine" and the first and second figures denote the type of functional failure and the corresponding failure mode respectively). Information was extracted from the Supervisory Control and Data Acquisition (SCADA) system for a period of 6 years. The SCADA system records failures and the date and time of occurrence; this was used in conjunction with maintenance Work Orders (WOs) of the same period to ascertain the specific type of failure and the components involved. Over this period, the catastrophic failure (by "catastrophic" in this case, we mean failures beyond repair which require replacement of the system) of a gearbox (failure mode WT-1-6) occurred twice, while the catastrophic failure of a generator (failure mode $W T-1-8$ ) occurred on one occasion.

Activities for inspection of wind turbines drive trains were obtained from the collaborating wind farm operator (see table 4) while current market prices of vibration monitoring systems for failure modes WT-1-3, WT-1-4, WT-1-5, WT-1-6 WT-1-7 and WT-1-8 were obtained from vendors of condition monitoring system (see table 5).

\subsection{Failure consequences}

Our analysis is based on the following equations, using functions given in the Nomenclature:

$$
\begin{aligned}
& T C_{M T}=\left(C_{M T}+C_{T P}+C_{L d}+C_{O L d}\right)\left(1+\frac{V_{A T}}{100}\right) \\
& T C_{L B}=N_{P n} \times N_{d y} \times W_{h r} \times L_{R T} \\
& T C_{A S}=\left(C_{C R} \times N_{d y}\right)+\left(C_{C R} \times N_{d y} \times \frac{V_{A T}}{100}\right) \\
& T_{P L}=\left(L_{h c}+R_{d y}\right) \times 24 \times W T_{P R} \times C_{E H} \times\left(\frac{C_{f}}{100}\right)
\end{aligned}
$$

\section{(4)}

$$
F_{C}=T C_{M T}+T C_{L B}+T C_{A S}+T_{P L}
$$

$$
P W=\frac{1}{(1+d)^{T}}
$$

$$
P W A=\frac{(1+d)^{T}-1}{d(1+d)^{T}}
$$

$$
N P V_{T B M}=T A_{C I} \times P W A
$$




$$
N P V_{C B M}=\left(C_{c m} \times P W\right)+\left(A M_{c m}+A C_{C B M}\right) P W A
$$

(9)

$$
A_{C R}=\alpha F_{C} N_{T}
$$

$$
A^{*}=A_{i} \mid S_{i}=\bigvee_{i=1, n} \sum_{j=1}^{m} W_{j} \cdot S_{i j}
$$

$$
A^{*}=A_{i} \mid B T C_{i}=\bigvee_{i=1, n} \frac{S_{i}}{N P V_{i}}
$$

Table 6 shows the failure consequences of critical components of a $600 \mathrm{~kW}$ wind turbine expressed in financial terms. These were determined by using equation 5 and the data in table 3, taking into account cost of material (Equation 1), cost of labour (Equation 2), cost of access (Equation 3) and production losses (Equation 4).

A single day outage of a $600 \mathrm{~kW}$ wind turbine (at $33 \%$ capacity factor and $£ 50 / \mathrm{MWh}$ energy value) would result to a revenue loss of about $£ 237 /$ day. Moreover onshore wind farms have the potential to operate at higher average capacity factors which results to a greater loss of revenue. Figure 1 shows the effect of capacity factors and down times on revenue generation of a $600 \mathrm{~kW}$ wind turbine. A month down time at 33\% and 36\% capacity factors will result to a revenue loss of $£ 7,128$ and $£ 7,776$ respectively, approximately $8 \%$ of the total annual revenue. Furthermore, the effects of two or more turbines failure on revenue generation are significantly higher. A month outage of seven $600 \mathrm{~kW}$ wind turbines at $33 \%$ capacity factor will result to a revenue loss of about $£ 49,896$. Hence, implementing a Failure Based Maintenance strategy only, where a certain number of wind turbines are allowed to fail before repairs are carried out will result in a significant loss of revenue in addition to the effect on the electricity network and cost of component replacement, given that, the lead time to supply most of the critical components ranges between 3-4 months.

\subsection{Selection of CBM task}

The RCM II Decision Diagram [11] was used to select suitable on-condition tasks also known as the Condition-Based Maintenance activities. These were selected on the assumption that an appropriate condition monitoring task is available to detect incipient dominant failure modes (that occur gradually with warning signs and are independent of age) so that actions can be taken to avoid the resultant consequences.

Vibration analysis was identified as the suitable condition based maintenance technique to mitigate dominant causes of failure modes WT-1-3, WT-1-4, WT-1-5, WT-1-6, WT-1-7, $W T-1-8, W T-1-12, W T-2-7$ and $W T-2-8$ while strain gauge measurements were employed for dominant causes of failure modes; WT-1-1, WT-1-2, WT-2-1, WT-2-2, WT-2-4, WT-25, and WT-2-6. Catastrophic failures of critical components such as the blades, main bearings and shaft, gearbox and associated components, the generator and associated components, towers and foundations should therefore be detectable and prevented through the application of appropriate CBM activities.

\subsection{Economic analysis of CBM and comparison with TBM}


The economic life of a wind turbine is 20 years [26-27] but an analysis period of 18 years is used in this paper to account for the 2 years all-in-service contract and obsolescence with changing technology. The corporate organisation of the collaborating wind farm operator utilises a discount rate of $8.2 \%$ for all financial analysis. Also, a spare pool of 1 gearbox, 1 generator, 3 blades etc is held by the wind farm under the TBM strategy. If any of these systems fail and it can not be repaired in-situ, the failed system is replaced with a spare before repairs are carried out and then transferred into the spare pool (note; the maximum number of spares that can possibly be in the re-supply chain of the wind farm at one time is beyond the scope of this paper). Using this information and the data in tables 4 and 5, the economics of TBM and CBM are evaluated and compared.

The Present worth (PW) and Present Worth per Annum (PWA), which is used for discounting initial non-recurring costs and annual recurring costs respectively, are determined by using equations 6 and 7 to obtain the values of 0.24 and 9.24 respectively. Then, the Net Present Value (NPV) of TBM and CBM, are calculated by using equations 8 and 9 respectively to obtain the values of $£ 122,085$ and $£ 239,106$ respectively. The results show that scheduled inspection of the drive trains of wind turbines is the most cost effective option over the 18 year life-cycle with a total savings of about $£ 117,021$. Indeed, the NPV of inspection $(£ 122,085)$ is less than the initial capital cost of installing condition monitoring systems $(£ 199,600)$.

\subsection{Uncertainties and risks assessment}

The NPV analysis deals with future costs which invariably contain uncertainties and risks that require critical assessments to ensure the accuracy of results for valid decision making. A probabilistic approach of Crystal Ball Monte Carlo simulation was used to assess the risks and uncertainties of the key variables in the Net Present Value calculations. After a 100,000 simulations, the results presented in Figures 3 and 4 shows no significant effect of uncertainties on the NPVs of TBM and CBM.

\subsection{Evaluation of non-financial factors}

An economic analysis based on purely financial criteria is not in itself adequate for valid decision making [28]. Non-financial factors, which are not reducible to monetary values should be identified and incorporated into the overall economic analysis [28-29]. A maintenance strategy that is appropriate for a specific physical asset should be reliable to uphold the integrity of the asset and also to fulfil all statutory and health and safety requirements. These non-financial factors are fundamental and can not be compromised in the selection of a suitable maintenance strategy. In Figure 2, a screening model [30] for maintenance strategies is presented and a weight of 3 (i.e. good) was established as the minimum standard requirement for each of the decisive criteria. In addition to these factors, five other criteria were identified. These includes 'fault detection' which is the ability to discover faults at an early stage so that appropriate actions can be taken to avoid the consequences; 'fault identification' which is the ability to identify the subsystem or component most relevant to diagnosing the fault within the shortest time possible; 'fault diagnosis' is the ability to determine the cause of the fault within the shortest time possible; 'process recovery' is the ease of rectifying the fault in good time and 'Efficiency' is the effectiveness of restoring the asset to a normal operating condition. These were assessed using the Weighted Evaluation (WE) technique [28-29] and the result is presented in Figure 5. It is worth noting however, that the non-financial factors can be subjective and Figure 5 was established through discussion with wind farm operators.

The WE approach consists of two processes; first, assessment criteria are identified and the weights of their relative importance are established. These are sequentially compared 
in pairs and the most vital criterion is scored according to its comparative preference of scale 1 to 4, for example in Figure 5, criterion ' $A$ ' (fault detection) is compared with criterion ' $E$ ' (health and safety), $E$ is found to be more important than $A$ and it is a major preference, hence the value ' $E-4$ ' was recorded. The scores of each criterion are summed up (Raw Score in Figure 5) and the final weights $W_{j}$ are determined such that the maximum weight is assigned a value of 10 (Weight of importance in Figure 5). Secondly, the rating $S_{i j}$ of each strategy (TBM and CBM) in terms of each criterion is determined on a scale of 1 to 5 (i.e. poor to excellent), for instance, the performance of CBM in terms of criterion ' $A$ ' (fault detection) was found to be 'good' (i.e. 3). These values were then multiplied by the corresponding criterion final weights $W_{j}$ and the summation gives the total score of the strategy (equation 11). As a rule, the best alternative $A^{*}$ should have the highest total score [28]. In Figure 5, the total scores of TBM and CBM are 105 and 142 respectively; this suggests that the CBM strategy is the best alternative.

\subsection{Benefit-To-Cost ratio evaluation}

The benefit-to-cost (BTC) ratio evaluation combines the results of the financial and the non-financial calculations to determine and compare the benefits derived from the competing options. The higher the ratio the better the benefit derived from the alternative. Equation 12 was used to determine the BTC ratio of TBM and CBM to obtain the values of 0.000860 and 0.000594 respectively (Figure 5). This indicates that the BTC ratio of CBM strategy is very low in comparison to TBM because of the high initial capital investments required for installing condition monitoring systems. Thus, for a successful future development of the wind industry, the costs of condition monitoring systems need to driven down to increase the benefits derived from the systems.

\subsection{Failure rates}

Condition monitoring systems are designed to identify incipient failures so that appropriate actions can be taken to prevent the failures from escalating to catastrophic events. Therefore it is absolutely necessary to assess failure rates of the critical components and incorporate these into the overall analysis. The failure rate (a) of failure modes $W T-1-3, W T-1-4, W T-1-6$ and $W T-1-8$ were estimated by determining firstly 'wind turbine operational years' which is the product of the number of turbines in a wind farm (26) and the period under consideration (6 years) to obtain 156 operational years. The number of events for each failure mode is then divided by the wind turbine operational years to get the failure rate of the components. For example, 2 catastrophic failures of a gearbox occurred in the period under consideration to give $a=0.01282$ per year. These were further converted into annual cash reservations using equation 10; the summation ( $£ 32,150$ per annum) is discounted by PWA to get a Net Present Value of $£ 297,173$. Hence, the actual NPV of TBM is established by summing the NPV of inspection and NPV of annual cost reservation to get $£ 419,258$. Using this value to repeat the WE and BTC ratios shows CBM is the most cost effective strategy with a total savings of $£ 180,152$ over the 18 year life cycle..

\section{CONCLUSIONS AND FUTURE WORK}

This paper has presented a methodology for selecting suitable maintenance strategies for wind turbines using a hybrid of RCM and ALCA techniques, and has used the methodology to determine an appropriate CBM strategy for a $26 \times 600 \mathrm{~kW}$ wind farm. Industrial data pertaining to the wind farm has been sourced from the farm operator and have been collated to determine inspection activities and failure history of the wind turbines. Current market prices of critical components of the wind turbines as well as the condition monitoring systems have been sourced from manufactures and vendors. The RCM approach has been used to determine wind turbines failure modes, causes and effects. 
Failure consequences of critical components have been determined and expressed in financial terms. Suitable CBM tasks have been determined and compared with TBM activities using the ALCA technique. In the comparison, the NPV of TBM and CBM has been calculated; the non-financial factors of the two strategies have been assessed using the WE technique and the benefit-to-cost ratio of each of the option has been calculated. It has been shown that comparison of the NPV is not absolute for a valid decision making since it considers only financial criteria and the selection of a suitable maintenance strategy depends upon the failure characteristics of the wind turbines. Thus failure data was extracted from the SCADA system of the wind farm and was validated by the maintenance work orders of the same period. The failure rate of critical components was calculated and included in the analysis. The overall result shows CBM is the most cost effective option with a total savings of $£ 180,152$ over 18 year life-cycle. This methodology is sufficiently generic to any industry that employs physical assets. Further research work is being undertaken to optimise the CBM activities using a delay-time maintenance mathematical model, this will be reported in a future paper.

\section{ACKNOWLEDGEMENTS}

The authors would like to acknowledge the very helpful comments of an anonymous referee.

\section{REFERENCES}

[1] Global Wind Energy Council (n.d.). URL: info@gwec.net

[2] Marafia, A. H. and Ashour H. A., Economics of Offshore/On-shore Wind Energy Systems in Qatar, Renewable Energy, 2003, 28(12), 1953-1963.

[3] Junginger, M., Faaij, A. and Turkenburg, W. C. Global experience curves for wind farms, Energy Policy, 2005, 33(2), 133-150.

[4] Learney, V. C., Sharpe, D. J. and Infield, D., Condition monitoring technique for optimisation of wind farm performance, International Journal of COMADEM,1999, 2(1), 513.

[5] Rademakers, L. W. and Verbruggen, T., Maintenance manager to control operation and maintenance of offshore wind farms, International Journal of Environment and sustainable Development, 2002, 1(4), 370-378.

[6] Conover, K., VandenBosche, J., Rhoads, H. and Smith, B., Review of operation and maintenance experience in the DOE-EPRI wind turbine verification program, Proceedings of American Wind Energy Association's WindPower 2000, NREL/CP-500-28620.

[7] Verbruggen, T. Wind turbine operation and maintenance based on condition monitoring WT- $\Omega$ final report, Technical Report, ECN-C-03-047, 2003, Energy Centre Netherlands.

[8] Thorpe, C., Condition-Based Maintenance for CVN-21and DD, Empfasis, 2005, URL: http://www.empf.org/empfasis/july05/cbm705.htm [accessed August 2006]

[9] Arthur, N. and Dunn, M., Effective Condition Based Maintenance of reciprocating compressors on an offshore oil and gas installation, IMechE International Conference on Compressor and their system, 2001.

[10] Saranga, H. and Knezevic, J., Reliability prediction for Condition-Based maintained systems, Reliability Engineering and System Safety, 2001, 71, 219-224.

[11] Moubray, J., Reliability-Centred Maintenance II, Butter-Heinemann, 1991.

[12] Clayton, B. R., Dutton, A. G., Aftab, N., Bond, L., Lipman, N. H. and Irving, A. D., Development of structural condition monitoring techniques for composite wind turbine blades, Proceedings of European Community Wind Energy Conference, 1990, 10-14.

[13] Philippidis, T. P. and Vassilopoulos, A. P., Life prediction methodology for GFRP laminates under spectrum loading, Renewable Energy, 2004, 35, 657-666. 
[14] Caselitz, P., Giebhardt, J. and Mevenkamp., Application of condition monitoring system in wind energy converters, Proceedings of European Wind Energy Council ${ }_{\perp}$ Dublin, 1997, 579-582.

[15] Wilkinson, M. R. and Tavner, P. J. Extracting condition monitoring information from a wind turbine drive train, Proceedings of the 39th International Universities Power Engineering Conference, IEEE Cat. No. 04EX858, 2004, 1(1), 591-595.

[16] DeHaas, J. W., Performance, How to measure maintenance effectiveness, Asset management, 1997, 12 (4).

[17] Woodhouse, J., Combining the best bits of RCM, RBI, TQM, Six-Sigma and other solutions, Institute of Asset Management publication, 2002, URL http://www.iamuk.org/downloads/ertc\%202001\%20paper.pdf [accessed August 2006]

[18] Wintle, J. et al., Best practice for risk based inspection as a part of plant integrity management, Health and Safety Executive, Suffolk, Great Britain, 2001.

[19] Favvennec, J. P. Refinery Operation and Management, Technip Paris, 2001.

[20] Latino, K. C., RCFA+RCM= formula for successful maintenance, Plant Engineering magazine, 1997, URL: http://www.reliability.com [accessed September 2006]

[21] Moubray, J., The case against streamlined RCM, 2000, http://www.aladon.co.uk$\angle 13$ case.html.

[22] Marquez, F. P. G., Schmid, F. and Collado, J. C., A Reliability centred approach to remote condition monitoring. A railway points case study, Reliability Engineering and System Safety, 2003, 80, 33-40.

[23] Decade, V. S. and Modak, J. P., Maintenance strategy for tilting table of rolling mill based on reliability considerations, Reliability Engineering and System Safety, 2003, 80, $1-18$.

[24] Roused, M., Reliability-Centred Maintenance, Reliability Engineering and System Safety, 1998, 60, 121-132.

[25] Wind Turbine Standards IEC 61400-22, The International Electro-technical Commission, 2000, Technical report. http://www.awea.org/standards/iec stds.html [accessed July 2006]

[26] Lenzen, M and Munksgaard, J. (2002) Energy and CO2 life-cycle analyses of wind turbines- review and applications, Renewable Energy, 2002, 26(3), 339-362.

[27] Kaldellis, J.K. and Gavras, Th. J., The economic viability of commercial wind plants in Greece: A complete sensitivity analysis, Energy Policy, 2000, 28(8), 509-517.

[28] Kirk, S.J. and Dell'Isola, A.J., Life Cycle Costing for Professionals. McGrew-Hill Book Company, New York, 1995.

[29] Kishk, M., Towards Effective Consideration of non-financial factors in the design and management of construction assets. Journal of financial management of property and construction, 2002, 7(3), 163-174.

[30] Kishk, M. and Pollock, R. (2004). An extended whole-life costing frame work to achieve best value. Proceedings of the international Construction Conference: Responding to Change, 2004, Leeds Metropolitan University.

\section{LIST OF TABLES AND FIGURES}

Table 1 Functional Failure and Failure Modes for Horizontal Axis Wind Turbines

\begin{tabular}{lll}
\hline Function & Functional failure & Failure modes \\
\hline $\begin{array}{l}W T \text { to covert } \\
\text { wind kinetic }\end{array}$ & $\begin{array}{r}W T-1 \text { Complete loss } \\
\text { of energy conversion }\end{array}$ & $\begin{array}{l}W T-1-1 \text { Catastrophic blade failure } \\
W T-1-2 \text { Catastrophic hub failure }\end{array}$
\end{tabular}




\author{
energy into \\ electrical \\ energy \\ within \\ defined \\ speed limit \\ (cut-in and \\ cut-out)
}

\begin{tabular}{|c|c|}
\hline capability & $\begin{array}{l}\text { WT-1-3 Main bearing failure } \\
W T-1-4 \text { Main shaft failure } \\
W T-1-5 \text { Shaft-gearbox coupling failure } \\
W T-1-6 \text { Gearbox failure } \\
W T-1-7 \text { Gearbox-generator coupling failure } \\
W T-1-8 \text { Generator failure } \\
W T-1-9 \text { Meteorological system failure } \\
W T-1-10 \text { Premature brake activation } \\
W T-1-11 \text { Electrical system failure } \\
W T-1-12 \text { Tower failure } \\
W T-1-13 \text { Foundation failure }\end{array}$ \\
\hline $\begin{array}{l}\text { WT-2 Partial loss of } \\
\text { energy conversion } \\
\text { capability }\end{array}$ & $\begin{array}{l}\text { WT-2-1 Crack in blade } \\
\text { WT-2-2 Deteriorating blade root stiffness } \\
\text { WT-2-3 Blades at different pitches } \\
\text { WT-2-4 Dirt build-up on blades } \\
\text { WT-2-5 Ice build-up on blades } \\
\text { WT-2-6 Damping in blades } \\
\text { WT-2-7 Hub spins on shaft } \\
\text { WT-2-8 Low speed shaft misalignment } \\
\text { WT-2-9 Nacelle not yawing } \\
\text { WT-2-10 Nacelle yaws too slowly } \\
\text { WT-2-11 Nacelle yaws too fast } \\
\text { WT-2-12 Large yaw angle } \\
\text { WT-2-13 Cable twist } \\
\text { WT-2-14 Wind speed measurement error } \\
\text { WT-2-15 Wind direction measurement error }\end{array}$ \\
\hline$W T-3$ Over speeding & $\begin{array}{l}\text { WT-3-1 Controller failure } \\
W T-3-2 \text { Hydraulic system failure } \\
W T-3-3 \text { Pitching system failure } \\
W T-3-4 \text { Mechanical brake failure } \\
\text { WT-3-5 Grid connection failure }\end{array}$ \\
\hline
\end{tabular}

WT-1-3 Main bearing failure

WT-1-6 Gearbox failure

WT-1-7 Gearbox-generator coupling failure

$W T-1-12$ Tower failure

$W T-2-1$ Crack in blade

$W T-2-2$ Deteriorating blade root stiffness

WT-2-8 Low speed shaft misalignment

$W T-2-9$ Nacelle not yawing

$W T-2-10$ Nacelle yaws too slowly

Th

d speed measurement error

WT-3-1 Controller failure

WT-3-2 Hydraulic system failure

WT-3-5 Grid connection failure 
Table 2 Failure Modes and Effects Analysis (FMEA) for Horizontal Axis Wind Turbines

\begin{tabular}{|c|c|c|c|}
\hline Failure modes & Causes (level 1) & Causes (level 2) & Failure effects \\
\hline & & $\begin{array}{c}W T-1-1-2-2 \text { De-bonding of matrix } \\
\text { and fibre }\end{array}$ & See $W T-1-1-2-1$ \\
\hline & & $W T-1-1-2-4$ Fatigue & See $W T-1-1-2-1$ \\
\hline & $\begin{array}{l}W T-1-1-3 \text { Loose } \\
\text { blade-hub connection }\end{array}$ & WT-1-1-3-1 Damaged shrink disc & $\begin{array}{l}\text { Vibration \& noise exceeds relevant standard. Shrink disc } \\
\text { fails and eventual blades failure. }\end{array}$ \\
\hline \multirow[t]{3}{*}{$\begin{array}{l}W T-1-2 \text { Catastrophic } \\
\text { hub failure }\end{array}$} & $\begin{array}{l}\text { WT-1-2-1 Loose hub-main } \\
\text { shaft connection }\end{array}$ & See $W T-1-1-3-1$ to $W T-1-1-3-3$ & $\begin{array}{l}\text { Less wind speed transferred to shaft. Noise \& vibration } \\
\text { exceed relevant standard. Eventual hub \& blades failure. }\end{array}$ \\
\hline & $\begin{array}{l}W T-1-2-2 \text { Slip or spin on } \\
\text { shaft }\end{array}$ & See $W T-1-1-3-1$ to $W T-1-1-3-3$ & See $W T-1-2-1$ \\
\hline & $W T-1-2-3$ Fatigue & See $W T-1-1-4-1$ & See $W T-1-2-1$ \\
\hline
\end{tabular}


Table 3 Data for calculating failure consequences

\begin{tabular}{|c|c|c|c|c|c|}
\hline Materials & Blade & Main-bearings & Main shaft & Gearbox & Generator \\
\hline Cost of material $(£)$ & $28,000.00$ & $7,985.00$ & $9,024.00$ & $50,000.00$ & $19,000.00$ \\
\hline Cost of transportation $(£)$ at $4 \%$ of material cost & $1,120.00$ & 319.40 & 360.96 & $2,000.00$ & 760.00 \\
\hline Cost of Loading $(£)$ at $0.5 \%$ of material cost & 140.00 & 39.93 & 45.12 & 250.00 & 95.00 \\
\hline Cost of off loading $(£)$ at $0.5 \%$ of material cost & 140.00 & 39.93 & 45.12 & 250.00 & 95.00 \\
\hline Value Added Tax (\%) & 17.5 & 17.5 & 17.5 & 17.5 & 17.5 \\
\hline \multicolumn{6}{|l|}{ Labour } \\
\hline Number of person & 3 & 3 & 3 & 3 & 3 \\
\hline Number of days required to replace components & 2 & 2 & 4 & 3 & 2 \\
\hline Work hours per day & 8 & 8 & 8 & 8 & 8 \\
\hline Skilled labour rate per hour $(\mathfrak{f})$ & 50.00 & 50.00 & 50.00 & 50.00 & 50.00 \\
\hline \multicolumn{6}{|l|}{ Access costs } \\
\hline Cost of crane hire per hour including driver $(£)$ & 100.00 & 100.00 & 100.00 & 100.00 & 100.00 \\
\hline Number of hours per day & 24 & 24 & 24 & 24 & 24 \\
\hline Cost of crane hire/day including Mob \& Demob (£) & $2,400.00$ & $2,400.00$ & $2,400.00$ & $2,400.00$ & $2,400.00$ \\
\hline Number of days & 3 & 3 & 4 & 4 & 3 \\
\hline Value Added Tax (\%) & 17.5 & 17.5 & 17.5 & 17.5 & 17.5 \\
\hline \multicolumn{6}{|l|}{ Production loss } \\
\hline Lead time to supply material (days) & 180 & 21 & 30 & 120 & 60 \\
\hline Lead time to hire a crane (days) & 4 & 4 & 4 & 4 & 4 \\
\hline Number of repair days including travel time & 3 & 3 & 4 & 4 & 3 \\
\hline Hours per day & 24 & 24 & 24 & 24 & 24 \\
\hline Wind turbine power rating $(\mathrm{kW})$ & 600 & 600 & 600 & 600 & 600 \\
\hline Capacity factor $(\%)$ & 33 & 33 & 33 & 33 & 33 \\
\hline Cost of energy per MWh $(£)$ & 50 & 50 & 50 & 50 & 50 \\
\hline
\end{tabular}

Table 4 Inspection activities of $26 \times 600 \mathrm{~kW}$ wind turbine drive trains

\begin{tabular}{|c|c|c|}
\hline Number of wind turbines in wind farm $\left(\mathrm{NT}_{\mathrm{WF}}\right)$ & 26 & \\
\hline Rated power per wind turbine & 600 & $\mathrm{~kW}$ \\
\hline Capacity factor & 33 & $\%$ \\
\hline \multicolumn{3}{|c|}{ 6-monthly service inspection of drive train } \\
\hline Number of turbines serviced/day/ 2 personnel $\left(\mathrm{NT}_{\mathrm{SD}}\right)$ & 1 & turbine \\
\hline Number of full-service per year $\left(\mathrm{N}_{\mathrm{FS}}\right)$ & 2 & \\
\hline Number of full service days/year $=\left(\mathrm{NT}_{\mathrm{WF}} / \mathrm{NT}_{\mathrm{SD}}\right) \mathrm{N}_{\mathrm{FS}}$ & 52 & days \\
\hline Number of personnel $\left(\mathrm{N}_{\mathrm{Pn}_{\mathrm{n}}}\right)$ & 2 & \\
\hline Work hours per day $\left(\mathrm{W}_{\mathrm{hr}}\right)$ & 6 & hours \\
\hline Labour rate per hour $\left(\mathrm{L}_{\mathrm{RT}}\right)$ & 17 & pounds \\
\hline Annual cost of 6-monthly inspection $=52 \times \mathrm{N}_{\mathrm{pn}} \times \mathrm{W}_{\mathrm{hr}} \times \mathrm{L}_{\mathrm{RT}}$ & $10,608.00$ & Pounds \\
\hline \multicolumn{3}{|l|}{ Annual gearbox inspection } \\
\hline Number of gearbox inspected/day/2 personnel $\left(\mathrm{N}_{\mathrm{GB}}\right)$ & 6 & \\
\hline Number of inspection per year $\left(\mathrm{N}_{\mathrm{I}}\right)$ & 1 & \\
\hline Number of days $=\left(\mathrm{NT}_{\mathrm{WF}} / \mathrm{N}_{\mathrm{GB}}\right) \mathrm{N}_{\mathrm{I}}$ & 4.333 & days \\
\hline Number of personnel $\left(\mathrm{N}_{\mathrm{Pn}}\right)$ & 2 & \\
\hline Work hours per day $\left(\mathrm{W}_{\mathrm{hr}}\right)$ & 6 & hours \\
\hline Labour rate per hour $\left(\mathrm{L}_{\mathrm{RT}}\right)$ & 50 & pounds \\
\hline Annual cost of gearbox inspection $=4.33 \times \mathrm{N}_{\mathrm{Pn}} \times \mathrm{W}_{\mathrm{hr}} \times \mathrm{L}_{\mathrm{RT}}$ & $2,600.00$ & pounds \\
\hline Total Annual Cost of Inspection ( $10,608.00+2,600.00)$ & $13,208.00$ & Pounds \\
\hline
\end{tabular}


Table 5 CBM tasks of $26 \times 600 \mathrm{~kW}$ wind turbine drive trains

\begin{tabular}{|c|c|c|}
\hline Number of wind turbines $\left(\mathrm{NT}_{\mathrm{WF}}\right)$ & 26 & \\
\hline Rated power per wind turbine & 600 & $\mathrm{~kW}$ \\
\hline IMU 16 channel H/W \& S/W D5DA3/turbine $\left(\mathrm{C}_{\mathrm{IMU}}\right)$ & 7,300 & pounds \\
\hline Park server/ wind farm $\left(\mathrm{P}_{\mathrm{SF}}\right)$ & 2,500 & pounds \\
\hline Maintenance spares/ wind farm $\left(\mathrm{M}_{\mathrm{SF}}\right)$ & 7,300 & pounds \\
\hline WEBCON/turbine/annum $\left(\mathrm{WEB}_{\mathrm{CON}}\right)$ & 294 & pounds \\
\hline Diagonostic support vibration analysis consultancy/ wind farm/annum $\left(\mathrm{D}_{\mathrm{SV}}\right)$ & 1,800 & pounds \\
\hline Application engineering \& bearing inspection/wind farm/inspection/report $\left(\mathrm{AE}_{\mathrm{BI}}\right)$ & 600 & pounds \\
\hline Aptitude exchange licence/wind farm/annum $\left(\mathrm{AE}_{\mathrm{LF}}\right)$ & 696 & pounds \\
\hline \multicolumn{3}{|l|}{ Annual condition based servicing of drive trains } \\
\hline Number of turbines serviced/day/ 2 personnel $\left(\mathrm{NT}_{\mathrm{SD}}\right)$ & 6 & turbine \\
\hline Number of full-service per year $\left(\mathrm{N}_{\mathrm{FS}}\right)$ & 1 & \\
\hline Number of full service days/year $=\left(\mathrm{NT}_{\mathrm{WF}} / \mathrm{NT}_{\mathrm{SD}}\right) \mathrm{N}_{\mathrm{FS}}$ & 4.33 & days \\
\hline Number of personnel $\left(\mathrm{N}_{\mathrm{Pn}}\right)$ & 2 & \\
\hline Work hours per day $\left(\mathrm{W}_{\mathrm{hr}}\right)$ & 6 & hours \\
\hline Labour rate per hour $\left(\mathrm{L}_{\mathrm{RT}}\right)$ & 17 & pounds \\
\hline \multicolumn{3}{|l|}{ Costs of CBM activities } \\
\hline Capital Cost of Condition Monitoring $(\mathbf{C M})$ System $=\left(\mathrm{NT}_{\mathrm{WF}} \times \mathrm{C}_{\mathrm{IMU}}\right)+\mathrm{P}_{\mathrm{SF}}+\mathrm{M}_{\mathrm{SF}}$ & $199,600.00$ & pounds \\
\hline Annual maintenance cost of $\mathbf{C M}=\mathrm{WEB}_{\mathrm{CON}}+\mathrm{D}_{\mathrm{SV}}+\mathrm{AE}_{\mathrm{BI}}+\mathrm{AE}_{\mathrm{LF}}$ & $3,390.00$ & pounds \\
\hline Annual cost of condition-based servicing of drive trains $=4.33 \times \mathrm{N}_{\mathrm{Pn}} \times \mathrm{W}_{\mathrm{hr}} \times \mathrm{L}_{\mathrm{RT}}$ & 884.00 & pounds \\
\hline
\end{tabular}

Table 6 Failure consequences of critical components of a $600 \mathrm{~kW}$ wind turbine

\begin{tabular}{|l|r|r|r|r|r|}
\hline \multicolumn{1}{|c|}{ Failure Modes } & \multicolumn{5}{c|}{ Failure consequences $\mathbf{F}_{\mathbf{C}}(\mathfrak{f})$} \\
\cline { 2 - 6 } & $\mathrm{TC}_{\mathrm{MT}}$ & $\mathrm{TC}_{\mathrm{LB}}$ & $\mathrm{TC}_{\mathrm{AS}}$ & $\mathrm{P}_{\mathrm{LS}}$ & Total \\
\hline WT-1-1 Catastrophic blade failure & $34,545.00$ & $2,400.00$ & $8,460.00$ & $1,663.20$ & $47,068.20$ \\
\hline WT-1-3 Catastrophic main bearings failure & $9,851.49$ & $2,400.00$ & $8,460.00$ & $1,663.20$ & $22,374.69$ \\
\hline WT-1-4 Catastrophic main shaft failure & $11,133.36$ & $4,800.00$ & $11,280.00$ & $1,900.80$ & $29,114.16$ \\
\hline WT-1-6 Catastrophic gearbox failure & $61,687.50$ & $3,600.00$ & $11,280.00$ & $1,900.80$ & $78,468.30$ \\
\hline WT-1-8 Catastrophic generator failure & $23,441.25$ & $2,400.00$ & $8,460.00$ & $1,663.20$ & $35,964.45$ \\
\hline
\end{tabular}


Table 7 Effect of failure characteristics on maintenance strategy.

\begin{tabular}{|c|c|c|c|c|}
\hline $\begin{array}{r}\text { Number of turbines } \\
\text { Number of failure years }\end{array}$ & 26 & & & \\
\hline Failure Modes & $\begin{array}{c}\text { Number of } \\
\text { Event }\end{array}$ & $\begin{array}{c}\text { Failure rate } \\
\quad \alpha\end{array}$ & $\begin{array}{l}\text { Failure consequences } \\
\qquad F_{C}\end{array}$ & $\begin{array}{l}\text { Annual cost reservation } \\
\qquad \mathrm{A}_{\mathrm{CR}}\end{array}$ \\
\hline WT-1-3 Catastrophic bearings failure & 0 & 0 & $22,374.69$ & 0 \\
\hline WT-1-4 Catastrophic mainshaft failure & 0 & 0 & $29,114.16$ & 0 \\
\hline WT-1-6 Catastrophic gearbox failure & 2 & 0.01282 & $78,468.30$ & $26,156.10$ \\
\hline WT-1-8 Catastrophic generator failure & 1 & 0.00641 & $35,964.45$ & $5,994.08$ \\
\hline \multirow{3}{*}{\multicolumn{4}{|c|}{$\begin{array}{r}\text { Total } A_{\mathrm{CR}} \\
\mathrm{NPV} \text { of } \mathbf{A}_{\mathrm{CR}} \\
\left.\mathrm{NPV} \text { of TBM (Inspection }+\mathbf{A}_{\mathrm{CR}}\right)\end{array}$}} & $32,150.18$ \\
\hline & & & & $297,172.56$ \\
\hline & & & & $419,257.59$ \\
\hline
\end{tabular}

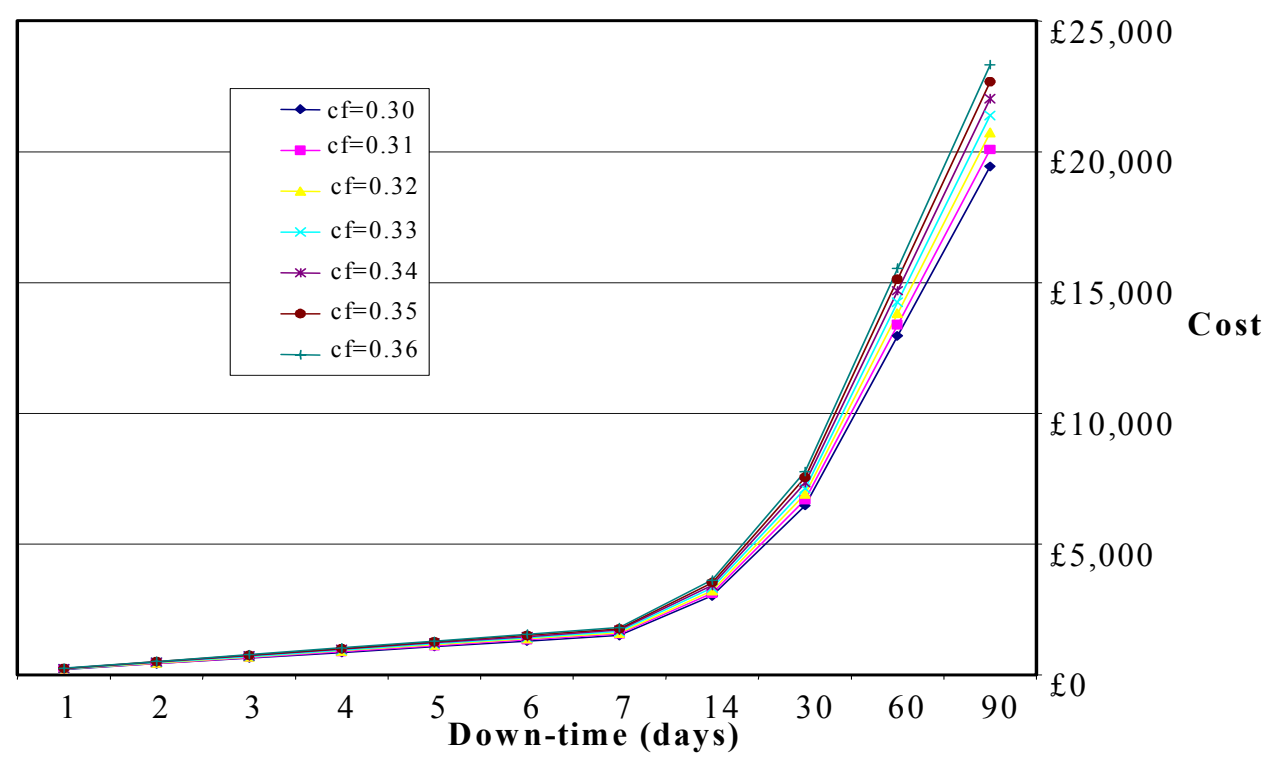

Figure 1 Effect of capacity factor and down time on revenue generation 


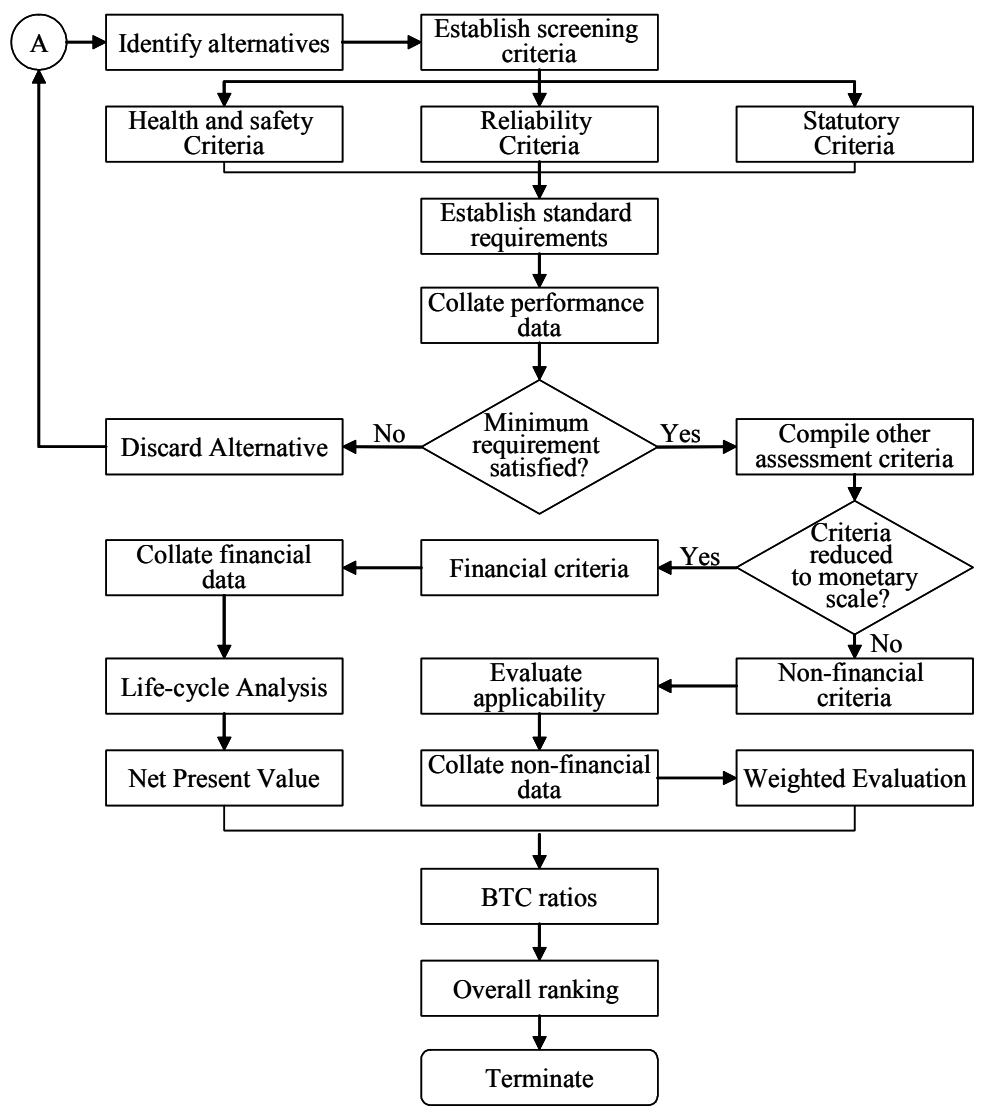

Figure 2 Model for screening options and criteria

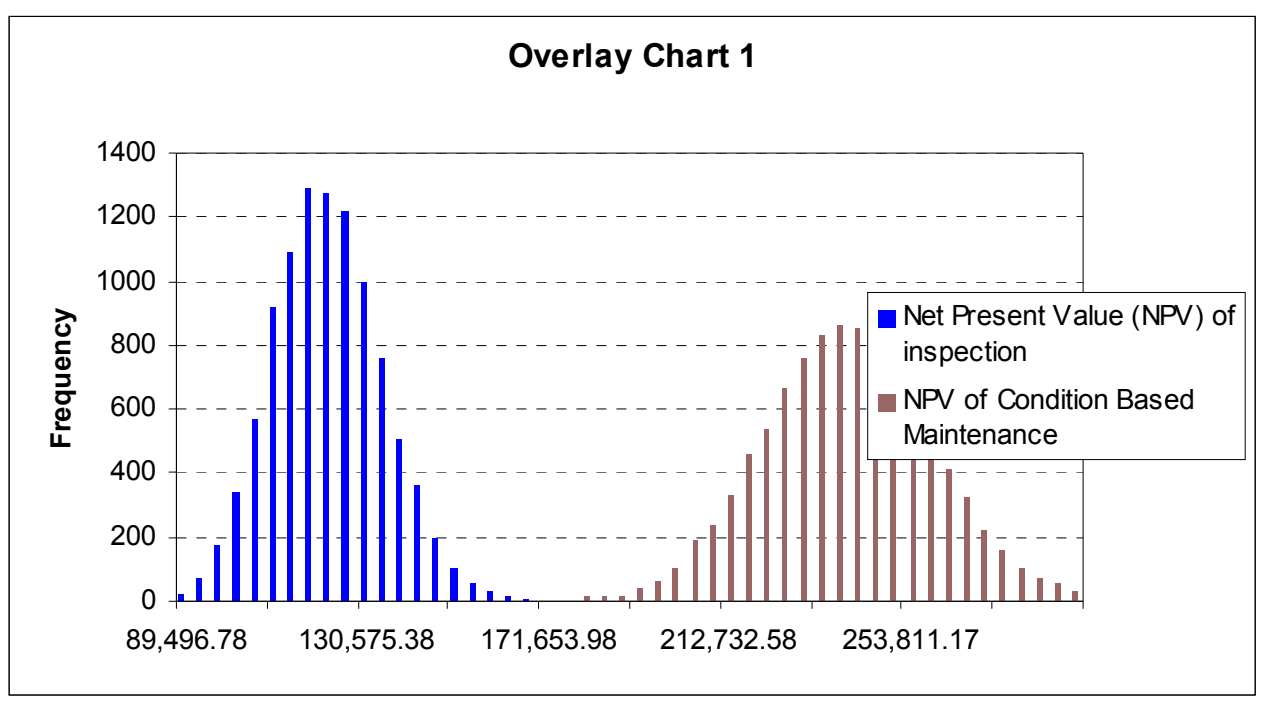

Figure 3 NPV overlay chart

Page 17 of 18 


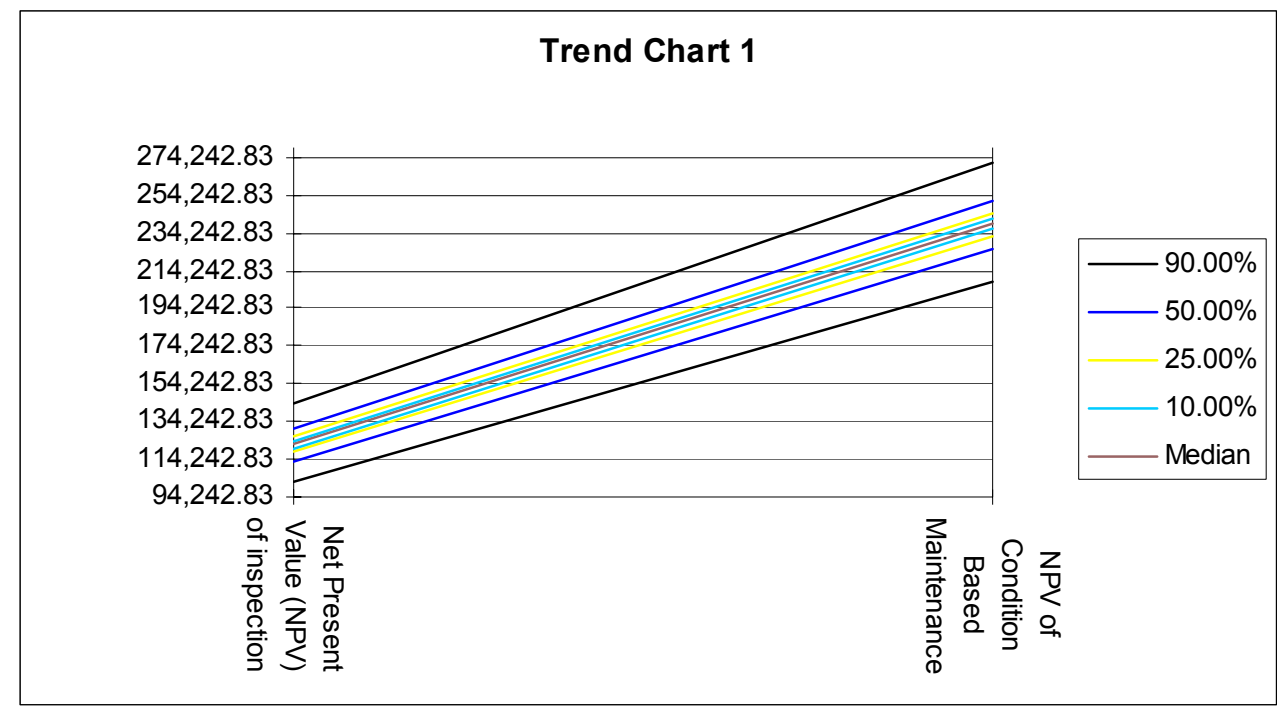

Figure 4 NPV trend chart

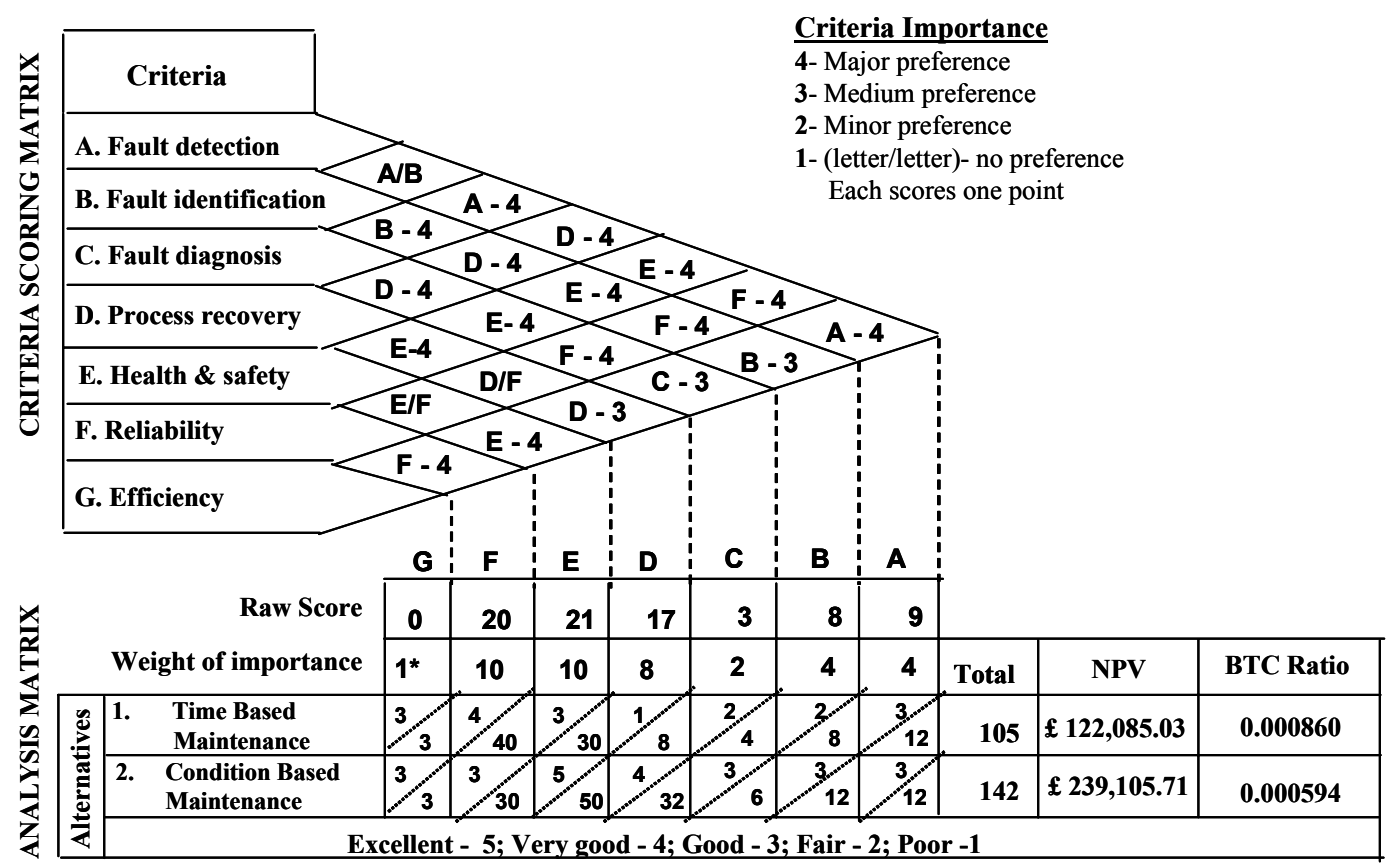

Figure 5 Weighted Evaluation of non-financial factors of TBM and CBM 